ISSN 1396-8149

Philipp J. H. Schröder

DEPARTMENT OF INTERNATIONAL BUSINESS

Real versus Tariff Liberalization: A Welfare Comparison under Monopolistic Competition

Aarhus School of Business

Fuglesangs Allé 4

DK-8210 Aarhus $V$ - Denmark

Tel. +4589486688

Fax +4589486125

www.asb.dk

Department of International Business 


\title{
Real versus Tariff Liberalization: A Welfare Comparison under Monopolistic Competition
}

\author{
Philipp J.H. Schröder* \\ Aarhus School of Business
}

January 2004

Address for correspondence: Aarhus School of Business, Fuglesangs Allé 4, DK 8210 Aarhus, Denmark, Tel.: +45 8948 6392, Fax: +45 89486125 , Email: psc@asb.dk

\begin{abstract}
A distinction between real trade costs (e.g. administration, border formalities, transport costs) and tariff costs is introduced into a standard monopolistic competition trade model. Driven by the number of firms, welfare under real trade barriers turns out to be lower than under an equivalent tariff barrier. Based on this finding, the paper shows that integration or rather liberalization measures (generating a certain increase in world trade) that reduce real trade barriers generate a larger welfare gain than integration consisting of a reduction in tariffs.
\end{abstract}

Key words: real costs, tariff costs, monopolistic competition, intraindustry trade, integration.

JEL classification: F12, F15

"Acknowledgments: This paper benefited from the comments and suggestions of Detlef Filip, Jan Guldager Jorgensen, Michael Phuger, Jan Rose Skaksen, the participants at the 4th Passauer Intenational Economics Workshop, 2002, and the participants of the ETSG annual conference in Kiel, 2002. The author alone is responsible for any remaining errors. 
Economic integration involves the reduction of trade costs; but reductions in real trade costs must be distinguished from reductions in tariff trade costs. ${ }^{1}$ By real trade costs, we mean costs that are real in terms of actually absorbing resources, such as administration costs, border formalities and transport costs. Such trade costs burn up resources because, for example, firms have to employ staff to deal with border formalities and administrative red tape or hire people to transport their goods, or they face additional costs from implementing foreign regulation and safety requirements. On the other hand, tariff trade costs, although very real for the individual firm, are unreal for the economy as a whole in the sense that they imply a reallocation of resources, that is, a tax that is imposed upon producers but eventually redistributed to consumers. As real and tariff trade barriers are different in nature, they have different effects on the economy, and removing the one or the other type of barrier, i.e. deep versus shallow integration, accordingly leads to different effects on welfare. ${ }^{2}$

Even though economists are well aware of the different nature of trade costs, generalizations and simplifications have to be made in formal models. In trade models with monopolistic competition beginning with the seminal work of Krugman (1980), a useful and preferred form of modelling trade costs is iceberg costs, where a fraction of goods is lost during transit; see, for example, Helpman and Krugman (1985) and Fujita et al. (1999). Thus, integration is understood as a reduction in these iceberg trade costs. This tool is useful, as the introduction of a separate transport sector or the reallocation of tariff revenues does complicate the analysis. Yet these approaches have been explored as well. For example, Venables (1987) goes beyond the iceberg costs assumption by modelling transport costs explicitly as marginal cost increases. Gros (1987) develops a monopolistic competition trade model with tariffs and redistributed revenues. Finally, Helpman and Krugman (1989) present various frameworks that deal with tariffs under imperfect competition.

The purpose of the present paper is to augment the literature by addressing both real and tariff trade costs in the same monopolistic competition framework, while explicitly solving for the welfare impact of integration, i.e. a reduction in either of the two types of costs. The paper develops a simple symmetrical two country trade model based on Krugman (1980). Real trade costs are modelled as marginal cost increases (following Venables (1987)), i.e. firms have to hire workers for administration or transport, etc. On the other hand, tariff costs are modelled as a specific tariff, with full redistribution of revenues to consumers. From a producer's point of view, both types of costs are identical, i.e. producers do not care if the costs they incur stem from real production costs or from a tariff. However, in a general equilibrium 
framework there is a difference in the number of firms under the two types of costs. Under a tariff trade cost, there exist more domestic and foreign firms than under an equal-sized real trade cost barrier. The reason is that, since real cost barriers absorb resources, they induce each firm to raise prices and cut exports. On the other hand, under a tariff trade cost, each firm raises prices and cuts exports, but because of the redistribution of tariff revenues, industry profitability is stabilized, thus attracting entry. From this intuition it becomes clear that welfare rankings between the two cost forms can be generated.

In terms of welfare effects - driven by the number of firms - the paper finds that when comparing a tariff cost barrier with a real cost barrier of equal size, the tariff barrier is associated with higher total consumer utility. Also, when setting the cost levels such as to maintain a certain volume restriction on imports, the tariff restriction is the best instrument to use. Concerning the central issue of economic integration, the paper finds that larger welfare gains are achieved from integration via real liberalization (reductions in real trade costs) than via tariff liberalization. Finally, if integration consists of a sequence of liberalizing real and tariff trade barriers, then reducing real cost barriers first and then reducing tariff barriers is welfare superior to the inverse sequence.

The differentiated nature of trade costs at the center of our analysis has always featured in empirical work. ${ }^{3}$ Baier and Bergstrand (2001) estimated the relative impact of transport cost reductions and tariff reductions on the growth in world trade. Starting from a monopolistic competition model, they found that both factors contribute significantly to the growth in world trade, but that income growth is the main explanatory factor behind it. Harrigan (1993) had previously used a monopolistic competition framework to estimate invisible trade barriers, and tariffs and transport costs and other visible nontariff barriers (real trade costs) featured in this work. Recently, Cudmore and Whalley (2003) studied the role of border delay and presented empirical evidence from the CIS region. Finally, European integration is a case at hand. Real trade barriers were tackled after the complete removal of tariff barriers was achieved among European countries. The early periods of European integration consisted predominantly of the creation of a customs union, with a common external tariff and internal tariff reduction/removal. Resourceconsuming border formalities and other red tape (real cost barriers) were addressed with the Single European Act in the 1990s, i.e. after the formation of a customs union (see e.g. Sapir, 1996; Allen et al., 1998; Buigues and Sapir, 2000 ). More recently, the introduction of a common currency, the euro, can be viewed as a reduction in real administrative trade costs. For example, the costs of managing hedging instruments are circumvented when trading 
within a common currency area. ${ }^{4}$ Given this evidence, there is no doubt that reductions in both real and tariff trade costs are important determinants of integration and trade, and that a formal examination of their effects on welfare is appropriate.

The formalization presented in this paper employs a number of restrictive assumptions which require further discussion. Firstly, in terms of the model, we use a simple standard version of the monopolistic competition model of intra-industry trade. Several characteristics of this model are exploited in order to derive explicit results and welfare rankings. For example, we use a utility function that generates equal and constant expenditure shares between home and foreign products. This feature plays an important role when determining the number of firms. In combination with the assumption of constant and equal fixed costs in the home and foreign markets, we arrive at the - undoubtedly unrealistic - result that each firm that is active on the home market finds it worthwhile to engage in exporting activity, i.e. all varieties that will be produced will also be exported. Other restrictive assumptions of the present model are the absence of a homogeneous goods sector and the equal size of countries. Because of this, zero tariffs (and zero real trade costs) turn out to be the social optimum. Once there is a homogeneous goods sector and once countries are sufficiently asymmetrical in size, there can be a rationale for non-zero tariffs (Gros, 1987). Also, the assumption of completely redistributed tariff revenues is probably at odds with reality, considering that bureaucracies are used to distribute the tariff revenues. For example, Venables (1987) has, inter alia, examined the opposite case of unilateral tariff policies with zero social value. Secondly, our classification into real and tariff trade costs is, though more elaborate than the simple iceberg cost assumption, far from exhaustive. In particular, both the real and tariff trade costs are modelled as variable costs, i.e. perunit costs. In contrast, tariffs - or exchange rate risks and insurance costs could be treated as ad valorem costs. More importantly, recent formal and empirical work emphasizes the role of fixed trade costs. This issue is not dealt with in the present model, where fixed costs are assumed to be constant and equal across markets. Venables (1994) first established that by introducing some additional fixed costs to exporting - representing e.g. the costs of setting up a distribution network abroad - firms become separated into nonexporting and exporting firms, i.e. not all varieties that are produced will be exported. Harris (1995) emphasizes communication costs as a cost to trade, and examines them as a fixed cost when communication channels have public good properties. Recently, Schmitt and Yu (2001) re-examined the relationship between scale economies and trade volume in a setting with firm-specific fixed costs of exporting, and Yu (2002) introduces a model where 
fixed costs of exporting, though equal across firms, can only be borne by a particular type of agent (entrepreneurs). Both settings generate exporting and non-exporting firms, a feature absent in the present model.

The paper is structured as follows. Section 1 introduces the formal model. In Section 2, the equilibria - prices, quantities and the number of firms - are derived for the two types of trade costs. Section 3 presents the welfare results of the analysis. Finally, Section 4 concludes the paper.

\section{The Model}

The starting point for the present model is Krugman's (1980) application of the Chamberlinian monopolistic competition approach - building on the contributions of Spence (1976) and Dixit and Stiglitz (1977) - to international trade.

It is assumed that the world consists of two symmetrical countries with firms producing in the same industry. In both countries, market conditions are characterized by monopolistic competition, increasing returns to scale in production and differentiated goods. The industry has a large number of potential variants that enter symmetrically into demand. Variants at home and abroad are different. Consumers want to consume both home and foreign variants.

The utility function in the model is based on Krugman (1981); it reinterprets the original feature of two industries as a distinction into home and foreign products and applies Krugman's (1980) specific functional form to both product groups. As the two countries are completely identical, it is sufficient to concentrate on the specification of the home country. Foreign variables are indicated by *. All individuals are assumed to have the same utility function,

$$
U=\ln \sum_{i=1}^{N_{H}} c_{H, i}^{\theta}+\ln \sum_{i^{*}=1}^{N_{M}} c_{M, i^{*}}^{\theta},
$$

where $0<\theta<1$ and $c_{M, i^{*}}$ is consumption of the $i^{*}$ th variant of imports and $c_{H, i}$ is consumption of the $i$ th variant of home products. In this set-up, the imports $(M)$ of one country equal the exports $\left(Z^{*}\right)$ of the other country and vice versa, i.e. trade is balanced. $N_{H}$ and $N_{M}$ define large numbers of potential variants in both home and foreign products. The number of variants actually produced, $n_{H}$ and $n_{M}$, is assumed to be large, although smaller than $N_{H}$ and $N_{M}$.

On the supply side, it is assumed that there exists only one factor of production: labor. Firms can produce their specific variant for the home 
market, the foreign market or both. ${ }^{5}$ When supplying both markets, each firm produces with the same cost function given by:

$$
l_{i}=\alpha_{H}+\alpha_{Z}+\beta x_{H, i}+\beta x_{Z, i}
$$

where $l_{i}$ is labor used in the production of the $i$ th variant of the home industry, $x_{H, i}$ is output of that variant for the home market, and $x_{Z, i}$ are the exports of that variant. This specification includes fixed costs, $\alpha_{H}$ and $\alpha_{Z}$, which are assumed to be some form of market-specific access costs (marketing, advertising, distribution), which are equal across countries, such that $\alpha_{H}=\alpha_{Z} \equiv \frac{\alpha}{2}$. Furthermore, $\beta$ is a constant marginal cost and hence average costs decline at a diminishing rate. Each variant is produced by only one firm, and each firm produces only one variant. Labor requirements (2) are converted into nominal costs by multiplying them by the wage rate, $w$.

The market clearing condition demands that the output of each variant should be equal to the total world consumption of that variant; more precisely that the markets for imports and home goods have to clear. Assuming full equality between the number of workers, $L$, and the number of consumers, this gives $x_{H, i}=L c_{H, i}$ and $x_{Z, i}=L^{*} c_{M, i}^{*}$. Due to symmetry $L=L^{*}$ and $c_{M, i}^{*}=c_{M, i^{*}}$. Also, labor market clearing demands $L=l_{i} n$ and $L^{*}=l_{i^{*}}^{*} n^{*}$. Since each variant behaves identically, subscripts $i$ and $i^{*}$ are omitted in the remainder of the paper.

This model follows the standard procedure for finding equilibrium and assumes free entry and exit of firms, utilizes the zero-profit condition, and evokes labor and goods market clearing (see e.g. Krugman 1980). The free trade equilibrium - with no real or tariff costs - is characterized by prices $p$, output per firm $x$, and the number of firms $n$.

$$
\begin{aligned}
& p_{H}=p_{M}=\frac{\beta w}{\theta}, \\
& x_{H}=x_{Z}=\frac{\theta \alpha}{2(1-\theta) \beta}, \\
& n_{H}=n_{M}=n=\frac{(1-\theta) L}{\alpha} .
\end{aligned}
$$

Firms produce equal quantities for the home and foreign market, and imported and home goods have the same price. Realizing that $n_{M}=n_{Z}$, (3) also shows that each firm will want to produce its variant for both the home and foreign market. 


\section{Equilibrium with real and tariff trade costs}

This section analyzes the effects of the two different forms of trade costs on the market equilibrium. All costs and their reductions will be applied bilaterally, that is, symmetrically.

\subsection{Market equilibrium with real trade costs}

Following Venables (1987), a real trade cost $\breve{t}>0$, alters a given firm's cost function (2). In other words, firms have to hire people to manage border formalities, to deal with red tape, to transport goods, etc. The trade cost is only encountered when exporting. The new cost function, when servicing both markets, becomes

$$
\check{l}=\alpha_{H}+\alpha_{Z}+\beta \check{x}_{H}+\beta \check{x}_{Z}+\check{t}_{Z} ;,
$$

where $\breve{l}$ is labor used in the production of a variant, and $\check{x}_{H}$ and $\check{x}_{Z}$ is the output of that variant for the home and export market respectively.

The profit of a home firm, producing a variant and servicing both markets, is given by $\check{\pi}=\check{p}_{H} \check{x}_{H}+\check{p}_{M}^{*} \check{x}_{z}-\check{l} w$, where $\check{p}_{M}^{*}=\check{p}_{M}=\check{p}_{Z}$, i.e. consumer import prices (identical to the export prices) are the same in both countries. Given constant fixed and marginal costs, the problem can be split into independent maximization for the home and foreign market:

$$
\begin{aligned}
& \check{\pi}_{H}=\check{p}_{H} \check{x}_{H}-\left(\frac{\alpha}{2}+\beta \check{x}_{H}\right) w, \\
& \check{\pi}_{Z}=\check{p}_{Z} \check{x}_{Z}-\left(\frac{\alpha}{2}+(\beta+\check{t}) \check{x}_{H}\right) w .
\end{aligned}
$$

Following the same procedures as above, the prices and quantities in each market and the resulting number of firms can be derived. The important characteristic of the real trade cost specification is that labor is actually absorbed in the process. When exporting, firms employ workers to carry out the transportation of goods, to deal with border formalities, etc. and hence will supply their output at a higher price to the foreign market. The workers engaged in the jobs associated with the real cost trade barrier still get wage $w$, and will demand both home and imported products - hence, total spending power is unchanged. However, some labor input is missing for 
the actual production of goods. Solving the model gives

$$
\begin{aligned}
& \check{p}_{H}=\frac{\beta w}{\theta}, \quad \check{p}_{Z}=\frac{(\beta+\check{t}) w}{\theta}, \\
& \check{x}_{H}=\frac{\alpha \theta}{2(1-\theta) \beta}, \quad \check{x}_{Z}=\frac{\alpha \theta}{2(1-\theta)(\beta+\check{t})}, \\
& \check{n}_{H}=\check{n}_{Z}=\check{n}=\frac{(1-\theta) L}{\alpha} .
\end{aligned}
$$

The number of firms is derived via the condition (stemming from the maximization of utility function (1)) that consumers will use equal shares of their income on imported goods and on home goods, i.e. $\check{p}_{j} \check{n}_{j} \check{x}_{j}=\frac{w L}{2}, j=$ $H, Z$. Comparing the resulting equilibrium (5) with the free trade case (3), we find that the supply of home goods to the home market is unchanged. Yet, for exports, prices have risen and quantities have fallen. However, the number of firms (variants) remains unchanged and each firm chooses to supply both markets. Thus, these results resemble the familiar effects of an iceberg trade cost (see e.g. Krugman, 1980).

\subsection{Market equilibrium with tariff trade costs}

The tariff differs from real costs, because - even though it enters the producer's problem as before - the tariff revenue remains in the system. We assume that no resources (labor) are absorbed when paying the tariff, and that all tariff receipts are redistributed to consumers at zero cost. ${ }^{6} \mathrm{~A}$ tariff set-up resembling the previous problem is generated by introducing a specific tariff $\hat{T}>0$. The profit function of a firm supplying both markets becomes $\hat{\pi}=\hat{p}_{H} \hat{x}_{H}+\hat{p}_{M}^{*} \hat{x}_{Z}-\hat{T} \hat{x}_{Z}-\hat{l} w$, where the cost function is identical to the initial version from (2). Defining the specific tariff in real terms by $\hat{t}=\frac{\hat{T}}{w}$ and separating the maximization for the two markets, the firm's profit function can be restated:

$$
\begin{aligned}
& \hat{\pi}_{H}=\hat{p}_{H} \hat{x}_{H}-\left(\frac{\alpha}{2}+\beta \hat{x}_{H}\right) w \\
& \hat{\pi}_{Z}=\hat{p}_{Z} \hat{x}_{Z}-\left(\frac{\alpha}{2}+(\beta+\hat{t}) \hat{x}_{H}\right) w .
\end{aligned}
$$

From the firm's perspective, the situation under a tariff trade barrier is identical to the situation under a real cost trade barrier. The specific tariff enters the exporting firm's profit function as an increase in marginal cost. Again, free entry and exit ensure that competition reduces industry profits 
to zero. The equilibrium is depicted by:

$$
\begin{aligned}
& \hat{p}_{H}=\frac{\beta w}{\theta}, \quad \hat{p}_{Z}=\frac{(\beta+\hat{t}) w}{\theta}, \\
& \hat{x}_{H}=\frac{\alpha \theta}{2(1-\theta) \beta}, \quad \hat{x}_{Z}=\frac{\alpha \theta}{2(1-\theta)(\beta+\hat{t})}, \\
& \hat{n}_{H}=\hat{n}_{Z}=\hat{n}=\frac{(1-\theta) L}{\alpha} \frac{2(\beta+\hat{t})}{2(\beta+\hat{t})-\theta \hat{t}} .
\end{aligned}
$$

The number of firms is calculated by utilizing the fact that half the income - including the income stemming from tariff revenues - is spent on home goods and half on imports, so that $\hat{p}_{Z} \hat{n}_{Z} \hat{x}_{Z}=\frac{w L^{*}+\hat{T} \hat{n}_{M}^{*} \hat{x}_{Z}}{2}$ must hold. Using the fact that $L=L^{*}$ and $\hat{n}_{Z}=\hat{n}_{M}^{*}$, one can calculate the number of firms that want to supply the foreign market and subsequently the number of firms that also want to supply the home market. As before, it turns out that $\hat{n}_{Z}=\hat{n}_{H}=\hat{n}$. In comparison to the case of a real trade barrier, price and quantity per firm are unchanged, but the number of firms has increased.

What causes this difference between the two forms of trade costs? Each firm, both under real trade costs and under the specific tariff, experiences an increase in its operating surplus on the foreign market, while the operating surplus on the home market remains unchanged. On the foreign market the following happens: the price that is set by firms in a sense overcompensates the increase in marginal costs. This occurs since firms price their goods as monopolists, i.e. set prices as a mark-up over marginal cost. Then, with a larger operating surplus, smaller product runs suffice to achieve breakeven, i.e. due to free entry/exit, all firms will just cover their fixed market access cost $\alpha_{Z}$. The two types of trade costs differ once examined in general equilibrium. In the tariff cost case, all tariff revenues are redistributed to the consumers, whereas under a real cost trade barrier, resources are used up. Thus under the tariff, spending power is larger than in the real cost case. Hence, under the tariff barrier, industry profitability is stabilized and more firms can enter the market before profits are competed to zero. However, as will be shown in Section 3, this increase in the number of firms in the tariff barrier case (which in fact means the number of firms exceeds that under free trade) is not a free lunch! The increased expenditures on fixed costs (due to more variants) are sub-optimal.

\subsection{Market equilibrium with both trade costs}

It is now possible to calculate the equilibrium when both types of trade costs are present. ${ }^{7}$ Formally denoting variables under the presence of both trade 
costs by ${ }^{\sim}$, and using $\check{\tau}$ and $\hat{\tau}$ as the real and tariff trade costs respectively, one arrives at the following profit functions for the two markets:

$$
\begin{aligned}
& \tilde{\pi}_{H}=\tilde{p}_{H} \tilde{x}_{H}-\left(\frac{\alpha}{2}+\beta \tilde{x}_{H}\right) w, \\
& \tilde{\pi}_{Z}=\tilde{p}_{Z} \tilde{x}_{Z}-\left(\frac{\alpha}{2}+(\beta+\check{\tau}+\hat{\tau}) \tilde{x}_{H}\right) w .
\end{aligned}
$$

From the firm's perspective, there are two separate increases in marginal cost; accordingly prices and firm output on the foreign market will behave in the same way as in the case of either a real or a tariff cost. A difference emerges in the number of firms. Using the same procedures as above, the equilibrium under the presence of both trade costs is described by:

$$
\begin{aligned}
& \tilde{p}_{H}=\frac{\beta w}{\theta}, \quad \tilde{p}_{Z}=\frac{(\beta+\check{\tau}+\hat{\tau}) w}{\theta}, \\
& \tilde{x}_{H}=\frac{\alpha \theta}{2(1-\theta) \beta}, \quad \tilde{x}_{Z}=\frac{\alpha \theta}{2(1-\theta)(\beta+\check{\tau}+\hat{\tau})}, \\
& \tilde{n}_{H}=\tilde{n}_{Z}=\tilde{n}=\frac{(1-\theta) L}{\alpha} \frac{2(\beta+\check{\tau}+\hat{\tau})}{2(\beta+\check{\tau}+\hat{\tau})-\theta \hat{\tau}} .
\end{aligned}
$$

The number of firms has to be calculated in two steps. First, by establishing the number of firms that wish to export via the condition $\tilde{p}_{Z} \tilde{n}_{Z} \tilde{x}_{Z}=\frac{w L^{*}+w \hat{n}_{M}^{*} \tilde{x}_{Z}}{2}$, using the fact that $L=L^{*}$ and $\tilde{n}_{Z}=\tilde{n}_{M}^{*}$. Second, the number of firms that also want to supply the home market can be derived from $\tilde{p}_{H} \tilde{n}_{H} \tilde{x}_{H}=\frac{w L+w \hat{\tau} \tilde{n}_{M} \tilde{x}_{M}}{2}$, using the fact that $\tilde{n}_{M}$ equals the $\tilde{n}_{Z}$ (just derived above) and that $\tilde{x}_{M}=\tilde{x}_{Z}$. As before, it turns out that $\tilde{n}_{Z}=\tilde{n}_{H}=\tilde{n}$, i.e. all firms that enter the industry will choose to supply both the home and the foreign market.

\section{Welfare results}

Utility function (1) and the characterizations of equilibrium (3), (5), (6) and $(7)$ are used to calculate total consumer utility under free trade $(U)$ and 
under the three cost cases.

$$
\begin{aligned}
& U=2 \ln \left(\frac{(1-\theta) L}{\alpha}\left(\frac{\alpha \theta}{2(1-\theta) \beta}\right)^{\theta}\right) \\
& \check{U}=U+\ln \left(\left(\frac{\beta}{\beta+\check{t}}\right)^{\theta}\right) \\
& \hat{U}=U+\ln \left(\left(\frac{2(\beta+\hat{t})}{2(\beta+\hat{t})-\theta \hat{t}}\right)^{2}\left(\frac{\beta}{\beta+\hat{t}}\right)^{\theta}\right), \\
& \tilde{U}=U+\ln \left(\left(\frac{2(\beta+\check{\tau}+\hat{\tau})}{2(\beta+\check{\tau}+\hat{\tau})-\theta \hat{\tau}}\right)^{2}\left(\frac{\beta}{\beta+\check{\tau}+\hat{\tau}}\right)^{\theta}\right) .
\end{aligned}
$$

It follows that $U>\check{U}, \hat{U}, \tilde{U}$, i.e. free trade utility is larger than utility under the presence of trade cost (see Appendix A.1). Also, and more importantly, the different cases can be clearly ranked.

Lemma 1 Given a total trade cost $t$, such that $t=\check{t}=\hat{t}=\check{\tau}+\hat{\tau}$, then

$$
U>\hat{U}(\hat{t})>\tilde{U}(\check{\tau}, \hat{\tau})>\check{U}(\check{t})
$$

Proof. See Appendix A.2. The utility under the tariff trade barrier (10) is larger than the utility under a real cost barrier (9), and accordingly is also larger than it would be under a mix of the two trade barriers (11), where the total trade cost is still fixed at $t$. Thus keeping total trade costs constant, utility is improved, as we substitute real trade barriers with tariffs. The intuition behind this ranking is as follows: Real trade barriers absorb resources (resources which give no utility), such that the total consumption volume is reduced, although the number of firms remains unchanged. A tariff barrier on the other hand, does not use resources on red tape, transport etc, but on creating more variants (firms) than is optimal. That is to say, a certain amount of pure waste $(\check{t})$ is converted into too much fixed cost $(\alpha)$ expenditure. The extra firms create some utility via the love of variety. Notice however, even with love of variety more firms are not always associated with higher utility: in other words, there can be too many firms. In fact, given a certain $\hat{t}$ and the resulting number of firms $\hat{n}$, consumers would be better off with slightly fewer firms, each producing a larger volume -- a situation closer to the free trade benchmark.

While the formulation of Lemma 1 assumes that the same total trade cost level exists, it would be more relevant to deal with an analysis of the same protection level. In particular, what level of the two different trade 
costs induces a certain import volume (global trade volume) and what are the associated utility levels? The free trade import volume is given by $M=x_{M} n$, plugging in the values from (3) gives $M=\frac{\theta L}{\partial \beta}$. Using (5) and (6), the import volumes under real and tariff trade costs are:

$$
\begin{aligned}
\check{M} & =\frac{\theta L}{2 \beta+2 \check{t}}, \\
\hat{M} & =\frac{\theta L}{2 \beta+(2-\theta) \hat{t}} .
\end{aligned}
$$

Then, in order to generate a reduction $\kappa ; \kappa \in(0, \ldots, M)$ of free trade imports with a real cost trade barrier, one needs to set $\check{t}=\frac{\lambda}{2}$, where $\lambda=$ $\frac{(2 \beta)^{2} \kappa}{\theta L-2 \beta \kappa}$. The same import level $(M-\kappa)$ is generated via the tariff $\hat{t}=\frac{\lambda}{2-\theta}$. Thus, - as is clear from intuition - the tariff barrier has to be higher than the real trade barrier in order to obtain the same protection level. Calculating the level of utility under protection gives rise to the following proposition.

Proposition 1 The attainment of a certain restricted import volume ( $M-$ r) with a tariff barrier leads to strictly higher utility than the attainment of the same restriction with a real cost trade barrier. In particular,

$$
\hat{U}\left(\hat{t}=\frac{\lambda}{2-r y}\right)>\check{U}\left(\check{t}=\frac{\lambda}{z}\right) \text {. }
$$

Proof. See Appendix A.3. Thus, from a welfare point of view, protection using a tariff is preferable to protection relying on real cost barriers, such as administrative red tape or safety regulations etc. This also means that a policy of converting real cost trade barriers into tariffs (say a form of tariffication), clearly improves welfare.

Next, we can turn to the effects of economic integration on welfare. What are the consequences of liberalizing any of the two trade barriers, given that both types of trade cost are present. Formally calculating $\tilde{n}_{M} \tilde{x}_{M}$, the import volume under the presence of both trade costs becomes:

$$
\tilde{M}=\frac{\theta L}{2 \beta+2 \tau+(2-\theta) \tilde{\tau}} .
$$

From $\tilde{M}$ one can see that a certain cut in tariffs has a smaller import-creating effect than an equal cut in the real trade cost: $\frac{\partial \tilde{M}}{\partial \ddot{t}}<\frac{\partial \tilde{M}}{\partial \hat{t}}<0$. An $\epsilon ; \epsilon \epsilon$ $(0, \ldots, M-\tilde{M})$ increase in imports can therefore be achieved via a reduction in tariffs (shallow integration) or via a reduction in real cost barriers (deep integration). In particular, in order to achieve such an $\epsilon$ increase in imports, the specific tariff $\hat{\tau}$ has to be reduced by $\frac{\gamma}{2-\theta}$, while the real cost barrier $\check{\tau}$ has to be reduced by $\frac{\gamma}{2}$, where $\gamma=\frac{(2 \beta+2 \tilde{\gamma}+(2-\theta) \hat{\gamma})^{2} \epsilon}{(2 \beta+2 \tilde{\tau}+(2-\theta) \hat{\gamma})+\theta L}$. Calculating the respective utility levels of the two cases leads to the following result: 
Proposition 2 Under the presence of both real and tariff trade barriers, given a permitted increase $\epsilon$ of imports $\tilde{M}$, the reduction of real costs is strictly preferable to the reduction of tariffs. In particular,

$$
\tilde{U}\left(\check{\tau}-\frac{\gamma}{2}, \hat{\tau}\right)>\tilde{U}\left(\check{\tau}, \hat{\tau}-\frac{\gamma}{2-\theta}\right) .
$$

Proof. See Appendix A.4. Proposition 2 states that for any level and mix of real and tariff trade costs and a given (permitted) increase in world trade from integration, national and thus also global welfare is higher if the trade increase is obtained via a liberalization of real cost instead of tariff cuts. Thus, deep integration is welfare superior to shallow integration.

There are important limitations to the stark result of proposition 2, namely that integration - the removal of trade barriers - is certainly not without cost. Although the removal of tariff trade barriers would be relatively cheap, the improvement of infrastructure in order to reduce transport costs (in the category of real trade costs) would be rather expensive. Still, many real trade barriers such as safety and regulation standards, issues of multiple currencies or administrative red tape, may not be very costly to remove, and the above result states that their removal would be preferable to tackling tariff cuts. To take European integration as an example, Proposition 2 suggests that for equal increases in trade volume, the single market programme (reductions of real cost trade barriers) has had a larger positive impact on welfare than the establishment of the common market did (reduction of tariff trade barriers).

What is the intuition behind this ranking of different integration policies? A cut in real costs $\check{\tau}$ not only increases imports (which increase utility), but also increases total tariff revenue, which has an additional positive impact on total consumer utility. On the other hand, the equivalent (in terms of import volume) cut in tariff trade costs $\hat{\tau}$ does increase imports, but at the same time reduces tariff revenue, and thus has less of a positive impact on consumer utility. This suggests a certain policy sequence. First the elimination of all removable real trade cost obstacles should take place while the tariff protection is maintained and then the tariff trade costs should be subsequently eliminated. More formally, treating the equilibria derived above as two separate stages of economic integration then - even when discounting is ignored - the following result can be stated:

Corollary 1 Given that an $\epsilon$ increase of imports $\tilde{M}$ is to be achieved by using the tools of real and tariff cost reduction equally, and given that two rounds of liberalization will take place, then a sequence in which reducing real trade costs precedes reducing tariff costs will be welfare superior to the inverse 
sequence. In particular,

$$
\tilde{U}\left(\check{\tau}-\frac{\gamma}{4}, \hat{\tau}\right)+\tilde{U}\left(\check{\tau}-\frac{\gamma}{4}, \hat{\tau}-\frac{\gamma}{4-2 \dot{\theta}}\right)>\tilde{U}\left(\check{\tau}, \hat{\tau}-\frac{\gamma}{4-2 \dot{ }}\right)+\tilde{U}\left(\check{\tau}-\frac{\gamma}{4}, \hat{\tau}-\frac{\gamma}{4-2 \dot{2}}\right) .
$$

Proof. Follows from Proposition 2. Corollary 1 formally states the above intuition, i.e. that real cost reductions ought to be the first step in integration, and should be followed by tariff reductions once the opportunities of costless reductions in real cost trade barriers have been exhausted.

\section{Conclusion}

The paper employs a simple two-country monopolistic competition model of international trade. As a new feature, the present work distinguishes between real trade costs (border formalities, red tape, transport costs, etc.) and tariff costs and integrates this explicitly into the model used. Real trade costs are resources-absorbing barriers, e.g. firms have to employ staff to deal with border formalities, transport is rendered costly due to deficient infrastructure, etc. On the other hand, tariff costs are a tax on foreign producers, but tariff revenues are eventually redistributed to consumers. Economic integration is characterized by reductions in both these types of costs. Accordingly, the present model is suitable to study both types of integration. Recall, however, that the model employs a number of restrictive assumptions. Some of the most critical issues are that the assumed utility function results in equal and constant expenditure shares on domestic and foreign products, that the model features no homogenous goods sector, and that the specification for both real and tariff trade costs is of a simple per-unit form, and thus ignores the possibility of ad valorem or fixed costs to exporting. While the benefit of this approach is a tractable setup with clear implications for the welfare consequences of economic integration, several of the assumptions might be at odds with empirical observations. The results of the model must be interpreted with these limitations in mind.

The paper demonstrates - in line with intuition - that depending on the type of trade cost there is a non-trivial difference between the resulting equilibria. In particular, more firms exist under a tariff cost trade barrier than under a real cost barrier or under free trade (no trade costs). However, in terms of total consumer utility, the number of firms under a tariff trade barrier is too high, and thus welfare is - although higher than under an equivalent real cost trade barrier - below the free trade level. Concerning the welfare impact from integration, the paper shows the following: If integration occurs owing to both a reduction in tariff costs and a reduction in real costs, the latter (deep integration) generates a larger utility gain than 
an equivalent reduction in tariff costs (shallow integration). Finally, a result concerning policy sequence emerges. Within the model, a sequence in which the reduction/removal of real cost trade barriers precedes reduction/removal of tariff barriers will be welfare superior to the inverse sequence. 


\section{A Appendix}

\section{A.1 Free trade utility versus utility under trade costs}

Proof that $U>\breve{U}, \hat{U}, \tilde{U}$. Utility under real trade costs (9) consists of free trade utility plus $\ln \left(\left(\frac{\beta}{\beta+t}\right)^{\theta}\right)$, since $0<\left(\frac{\beta}{\beta+t}\right)^{\theta}<1$, we have $U>\breve{U}$. Utility under tariff trade costs (10) consists of free trade utility plus $\ln g(\hat{t})$, where

$$
g(\hat{t})=\left(\frac{2(\beta+\hat{t})}{2(\beta+\hat{t})-\theta \hat{t}}\right)^{2}\left(\frac{\beta}{\beta+\hat{t}}\right)^{\theta} .
$$

Since, $g(0)=1$ and $\lim _{\hat{t} \rightarrow \infty} g(\hat{t})=0$ and since $g(\hat{t})$ is a monotone function in $\hat{t}$ we have $U>\hat{U}$. The utility under the presence of both trade costs (11) consists of the free trade utility plus $\ln f(\check{\tau}, \hat{\tau})$, where

$$
f(\check{\tau}, \hat{\tau})=\left(\frac{2(\beta+\check{\tau}+\hat{\tau})}{2(\beta+\check{\tau}+\hat{\tau})-\theta \hat{\tau}}\right)^{2}\left(\frac{\beta}{\beta+\check{\tau}+\hat{\tau}}\right)^{\theta} .
$$

Notice that $f(0, \hat{\tau})=g(\hat{\tau})$. Since $f(\check{\tau}, \hat{\tau})$ is monotone negative in $\check{\tau}$ we have $f(\check{\tau}, \hat{\tau})<g(\hat{\tau})<1$ for all $\check{\tau}, \hat{\tau}$. Also, $\lim _{\tilde{\tau} \rightarrow \infty} f(\check{\tau}, \hat{\tau})=0$ and $\lim _{\hat{\tau} \rightarrow \infty} f(\tilde{\tau}, \hat{\tau})=0$. Hence we have $U>\tilde{U}$.

\section{A.2 Proof of Lemma 1}

Given Appendix A.1, proof of inequality (12) reduces to demonstrating that $\hat{U}(\hat{t})>\tilde{U}(\check{\tau}, \hat{\tau})>\check{U}(\check{t})$. Utilising the definition $t=\check{t}=\hat{t}=\check{\tau}+\hat{\tau}$ in lemma 1 and the utility values derived in $(10),(11)$ and $(9)$, the relevant requirement becomes,

$$
\left(\frac{2(\beta+t)}{2(\beta+t)-\theta t}\right)^{2}\left(\frac{\beta}{\beta+t}\right)^{\theta}>\left(\frac{2(\beta+t)}{2(\beta+t)-\theta \hat{\tau}}\right)^{2}\left(\frac{\beta}{\beta+t}\right)^{\theta}>\left(\frac{\beta}{\beta+t}\right)^{\theta}
$$

which is always true.

\section{A.3 Proof of Proposition 1}

Utility under real cost protection, which results in the import volume $(M-\kappa)$, is given by $\tilde{U}^{p r i}=U+\ln \left(\left(\frac{\beta}{\beta+\frac{\lambda}{2}}\right)^{\theta}\right)$. Utility under tariff cost protection, which results in the import volume $(M-\kappa)$, is given by 
$\hat{U}^{p r t}=U+\ln \left(\left(\frac{2\left(\beta+\frac{\lambda}{2-\theta}\right)}{2\left(\beta+\frac{\lambda}{2-\theta}\right)-\frac{\theta \lambda}{2-\theta}}\right)^{2}\left(\frac{\beta}{\beta+\frac{\lambda}{2-\theta}}\right)^{\theta}\right)$, where both times $\lambda=\frac{(2 \beta)^{2} \kappa}{\theta L-2 \beta \kappa}$. Since,

$$
\left(\frac{\beta}{\beta+\frac{\lambda}{2}}\right)^{\theta}<\left(\frac{2\left(\beta+\frac{\lambda}{2-\theta}\right)}{2 \beta+\lambda}\right)^{2}\left(\frac{\beta}{\beta+\frac{\lambda}{2-\theta}}\right)^{\theta}
$$

reduces to $\frac{\lambda}{2}<\frac{\lambda}{2-\theta}$ inequality (13) will always hold.

\section{A.4 Proof of Proposition 2}

Utility, when an $\epsilon$ increase of imports $\tilde{M}$ is obtained via a cut in real trade costs, becomes $\tilde{U}^{\text {rcut }}=U+\ln \left(\left(\frac{2\left(\beta+\tilde{\tau}+\tilde{\tau}-\frac{\gamma}{2}\right)}{2\left(\beta+\tilde{\tau}+\hat{\tau}-\frac{\gamma}{2}\right)-\theta \hat{\tau}}\right)^{2}\left(\frac{\beta}{\beta+\tilde{\gamma}+\hat{\tau}-\frac{\gamma}{2}}\right)^{\theta}\right)$. Utility, when an $\epsilon$ increase of imports $\tilde{M}$ is obtained via a cut in tariff trade costs, becomes $\tilde{U}^{\text {tcut }}=U+\ln \left(\left(\frac{2\left(\beta+\check{\tau}+\hat{\gamma}-\frac{\gamma}{2-\theta}\right)}{2\left(\beta+\tilde{\tau}+\hat{\tau}-\frac{\gamma}{2-\theta}\right)-\theta \hat{\tau}+\frac{\theta \gamma}{2-\theta}}\right)^{2}\left(\frac{\beta}{\beta+\tilde{\tau}+\hat{\tau}-\frac{\gamma}{2-\theta}}\right)^{\theta}\right)$, where both times $\gamma=\frac{(2 \beta+2 \ddot{\tau}+(2-\theta) \hat{\tau})^{2} \epsilon}{(2 \beta+2 \dot{\tau}+(2-\theta) \hat{\tau}) \epsilon+\theta L}$. Since,

$$
\begin{aligned}
& \left(\frac{2\left(\beta+\check{\tau}+\hat{\tau}-\frac{\gamma}{2}\right)}{2(\beta+\check{\tau}+\hat{\tau})-\gamma-\theta \hat{\tau}}\right)^{2}\left(\frac{\beta}{\beta+\check{\tau}+\hat{\tau}-\frac{\gamma}{2}}\right)^{\theta}> \\
& \quad\left(\frac{2\left(\beta+\check{\tau}+\hat{\tau}-\frac{\gamma}{2-\theta}\right)}{2(\beta+\check{\tau}+\hat{\tau})-\gamma-\theta \hat{\tau}}\right)^{2}\left(\frac{\beta}{\beta+\check{\tau}+\hat{\tau}-\frac{\gamma}{2-\theta}}\right)^{\theta}
\end{aligned}
$$

reduces to $\frac{\gamma}{2}<\frac{\gamma}{2 \sim \theta}$ inequality (14) will always hold. 


\section{Notes}

${ }^{1}$ An equally suitable pair of terms found in the literature are cost-creating barriers versus rent-creating barriers.

${ }^{2}$ In the real world, the separation into real and tariff trade costs will often be blurred. For example, tariffs, by their very nature, create - apart form tariff revenue - a great deal of administrative costs and border formalities, i.e. real trade costs in the present definition.

${ }^{3}$ Beyond the analysis of directly measurable trade costs, there are a number of studies detecting implicit trade costs - all triggered by McCallum's (1995) revelation that the U.S.-Canadian border poses a big trade barrier. Implicit trade costs could be cultural or language differences, incorporation into the present model is still possible, as long as jumping such trade barriers can be dealt with at the firm level, e.g. by hiring staff.

${ }^{4}$ Rose (2000) and Rose and Wincoop (2001) estimate a substantial impact from currency unions on trade. Yet, recently these results have been criticized, see e.g. Nitsch (2002). Furthermore, exchange rate risk by itself would best be modelled as an ad valorem trade costs and not as a per-unit trade cost.

${ }^{5}$ As discussed in the introduction, the assumptions of the model lead to a constellation where each firm will in fact choose to produce for both markets.

${ }^{6} \mathrm{As}$ discussed in the introduction, this assumption presents a hypothetical case, considering that in the real world, bureaucracies are used to collect and distribute tariff revenues. Hence, any tariff will also generate some real trade costs, a feature not included in the present formalization.

${ }^{7}$ This version of the model enables us to study the effects of real cost reductions, while accounting for both the direct impact via increased imports, and the indirect impact via the increase in tariff revenue. 


\section{References}

Allen, Chris, Michael Gasiorek and Alasdair Smith (1998) "The Competition Effects of the Single Market in Europe." Economic Policy 13: 441-486.

Baier, Scott L. and Jeffrey H. Bergstrand (2001) "The Growth of World Trade: Tariffs, Transport Costs, and Income Similarity." Journal of International Economics 53: 1-27.

Buigues, Pierre-Andre and Andre Sapir (2000) "The Impact of the Single Market on the Big European Countries." In: Europe - Toward the next enlargement, International Handbooks on Economic Integration, Vol. 3: 133-153, Boston; Dordrecht and London: Kluwer Academic.

Cudmore, Edgar and John Whalley (2003) "Border Delays and Trade Liberalization." NBER Working Paper No. 9485.

Dixit, Avinash K. and Joseph E. Stiglitz (1977) "Monopolistic Competition and Optimum Product Diversity." American Economic Review 67: 297-308.

Fujita, Masahisa, Paul Krugman and Anthony J. Venables (1999) The Spatial Economy: Cities, regions, and international trade. Cambridge, MA: MIT Press.

Gros, Daniel (1987) "A Note on the Optimal Tariff, Retaliation and the Welfare Loss from Tariff Wars in a Framework with Intra-industry Trade." Journal of International Economics 23: 357-367.

Harrigan, James (1993) "OECD Imports and Trade Barriers in 1983." Journal of International Economics 35: 91-111.

Harris, Richard G. (1995) "Trade and Communication Costs." The Canadian Journal of Economics 28: 46-75.

Helpman, Ehanan and Paul Krugman(1985) Market Structure and Foreign Trade. Cambridge, MA: MIT Press.

Helpman, Elhanan and Paul Krugman (1989) Trade Policy and Market Structure. Cambridge, MA: MIT Press.

Krugman, Paul (1980) "Scale Economies, Product Differentiation, and the Pattern of Trade." American Economic Review 70: 950-959.

Krugman, Paul (1981) "Intraindustry Specialisation and the Gains from Trade." Journal of Political Economy 89: 959973. 
McCallum, John (1996) "National Borders Matter: Canada-U.S. Regional Trade Patterns." American Economic Review 85: 615623.

Nitsch, Volker (2002) "Honey, I Shrunk the Currency Union Effect on Trade." World Economy 25: 457-474.

Rose, Andrew K. (2000) "One Money, One Market: The Effect of Common Currencies on Trade." Economic Policy 15: 7-33.

Rose, Andrew K. and Eric van Wincoop (2001) "National Money as a Barrier to International Trade: The Real Case for Currency Union." American Economic Review 91: 386-390.

Sapir, Andre (1996) "The Effects of Europe's Internal Market Program on Production and Trade: A First Assessment." Weltwirtschaftliches Archiv 132: 457-475.

Schmitt, Nicolas and Zhihao Yu (2001) "Economies of Scale and the Volume of Intra-Industry Trade." Economics Letters 74: 127-132.

Spence, Michael (1976) "Product Selection, Fixed Costs and Monopolistic Competition." Review of Economic Studies 43: 217-235.

Venables, Anthony J. (1987) "Trade and Trade Policy with Differentiated Products: A Chamberlinian-Ricardian Model." The Economic Journal 97: $700-717$.

Venables, Anthony J. (1994) "Integration and the Export Behaviour of Firms: Trade Costs, Trade Volumes and Welfare." Weltwirschaftliches Archiv 130: $118-132$.

Yu, Zhihao (2002) "Entrepreneurship and Intra-Industry Trade." Weltwirschaftliches Archiv 138: 277-290. 


\section{Working papers from the Department of International Business}

96-1 Helle L. Lønroth: The Importance of Prior Acquisition Experience to the Creation of Shareholder Value in Danish International Acquisitions. October 1996.

96-2 Poul H. Andersen \& Jesper Strandskov: International Market Selection: A Cognitive Perspective. November 1996.

97-3 Helle L. Lønroth, Hanne Nørreklit \& Poul Erik Sørensen: Capital market pressure, corporate governance and their influence on long-term investments: The case of Denmark. August 1997.

97-4 Kent Nielsen, John Kjeldsen \& Steen Sørensen: Selvstændige, iværksættere og andet godtfolk. September 1997.

97-5 Edwin C. Duerr \& Mitsuko Saito Duerr: Japan's Changing Lifetime Employment System: Implications for Competitiveness. September 1997.

97-6 Poul Houmann Andersen \& Henrik Bendix Sørensen: Reputational Information: Its Role in Interorganizational Collaboration. October 1997.

97-7 H. Peter Holzer \& Hanne Nørreklit: Corporate Governance in the US and Germany - An Evaluation of the COSO Report.

97-8 Rajesh Kumar: Culture and the Dynamics of Competitive Collaboration: Sense Making In or Of Chaos?

98-1 Rajesh Kumar: Confucian Pragmatism vs Brahmanical Idealism Understanding the Divergent Roots of Indian and Chinese Economic Performance.

98-2 Hanne Nørreklit: Interne afregningsprincipper. Problemer - løsninger problemer.

98-3 Hanne Nørreklit \& Hanns-Martin W. Schoenfeld: Controlling Multinational Companies: An Attempt to Analyze Some Unresolved Issues.

98-4 Steen Thomsen \& Torben Pedersen: Ownership Structure and Economic Performance in the Largest European Companies.

98-5 Erik Strøjer Madsen and Kurt Pedersen: Quality, Export and Economic Growth.

99-1 Poul Houman Andersen, Niels Peter Mols \& Per Nikolaj D. Bukh: Cash Management relationships: Market-based and Credit-based Financial Systems. August 1999.

99-2 Kurt Pedersen: Market Morphology vs Industry Structure, a Suggested Interpretation. August 1999.

99-3 Poul Houman Andersen: Eksportsamarbejde blandt danske møbelproducenter. September 1999.

99-4 Jesper Strandskov and Kurt Pedersen: Pioneering FDIs into the Danish Bacon Industry: Building An Agro-industrial Diamond. October 1999.

99-5 Lars Gottlieb Hansen \& Jørgen Ulff-Moller Nielsen: The EU Public Procurement Regime. Does It Work? October 1999.

99-6 Rajesh Kumar: Brahmanical Idealism, Anarchical Individualism, and the Dynamics of Indian Negotiating Behaviox. November 1999.

00-1 Rajesh Kumar \& Kofi O. Nti: National Cultural Values and the Evolution of Process and Outcome Discrepancies in International Strategic Alliances. January 2000. 
00-2 Rajesh Kumar \& Jean-Claude Usunier: Management Education in a Globalizing World: Lessons from the French Experience. January 2000.

00-3 Rajesh Kumar \& V. Ranganathan: Interpretative Performance and the Management of Legitimacy in Understructured Environments. March 2000.

00-4 Hanne Nørreklit: The Balanced Scorecard: What Is The Score?-A Rhetorical Analysis of the Balanced Scorecard. March 2000.

00-5 Hanne Nørreklit: Benelux B.V. March 2000.

00-6 Rajesh Kumar: Negotiating Legitimacy In Interorganizational Interaction. May 2000.

00-7 Hanne Nørreklit: The Balanced Scorecard: What Is The Score?-A Rhetorical Analysis of the Balanced Scorecard. 2/ed. September 2000.

00-8 Jørgen Ulff-Møller Nielsen: Polish Foreign Trade: The Quality Catch-up and the Influence of Foreign Direct Investments. October 2000.

01-1 Annick Bourguignon, Veronique Malleret \& Hanne Nørreklit: American Management Theory and French Acts of Resistance. January 2001.

01-2 Jørgen Ulff-Møller Nielsen \& Teit Lüthje: Is the Classification of International Trade in Horizontal and Vertical Intra-industry Trade Usable? November 2001.

02-1 Rajesh Kumar: Culture And Emotions In Negotiations: An Overview. January 2002.

02-2 Maria Anne Skaates \& Bernard Cova: Marketing Industrial Project-Related Services: A Literature Review and Theoretical Synthesis. February 2002.

02-3 Rajesh Kumar \& Verner Worm: Social Capital and the Dynamics of Business Negotiations Between the Northern Europeans and the Chinese. February 2002.

02-4 Rajesh Kumar, U. Srinivasa Rangan \& Carlos Rufin: Negotiating Independent Power Projects: How To Survive The Perils Of Complexity. Marts 2002.

02-5 Annick Bourguignon, Veronique Malleret \& Hanne Nørreklit: The American Balanced Scorecard versus the French Tableau de Bord: an Ideological Perspective. May 2002.

02-6 Edwin C. Duerr and Mitsuko Saito Duerr: Japan's "Economic Miracle» and Current Problems. May 2002.

02-7 Jørgen Ulff-Møller Nielsen: Price Strategy in the EU: Suggestions to Chinese Exporters in the Light of Anti-Dumping. September 2002.

02-8 Poul Israelsen, Hanne Nørreklit \& Lennart Nørreklit: Validity of Management Control. Towards Constructivist Pragmatism. September 2002.

02-9 Rajesh Kumar: Making Acquisitions Work: The Role of Emotions. September 2002.

02-10 Mick Schou Rasmussen, Erik Strøjer Madsen and Kurt Pedersen: The Global Oil Industry. September 2002.

02-11 Poul Houman Andersen and Maria Anne Skaates: Ensuring Validity in Qualitative International Business Research. October 2002.

02-12 John A. Mathews: Competitive dynamics and economicleaming: An extended ressource-based view. October 2002.

02-13 John A. Mathews: Competitive advantages of the latecomer firm: Aressource. based account of industrial catch-up strategies. October 2002. 
02-14 Kurt Pedersen, Jesper Strandskov and Peter Sørensen: An International Business Blunder: Fennia 1913-16. November 2002.

02-15 Kurt Pedersen: Standardization in an International Perspective. November 2002.

02-16 Jesper Strandskov and Kurt Pedersen: Internationalization of Services: A Longitudinal Study of ISS International Service System, 1901-90. November 2002.

02-17 John A. Mathews: Strategizing vs. economizing: Theorizing dynamic competitive behavior in disequilibrium. November 2002.

02-18 Jørgen Ulff-Møller Nielsen and Kim Mortensen: Dynamic International Competitiveness of Transition Economies: What Do Trade Figures Tell Us? The Case of Poland and the Czech Republic. November 2002.

03-1 Maria Anne Skaates: Internationale kommunikationseffekter ved fremsendelse af danske vidensregnskaber på engelsk til kunder i Storbritannien og Tyskland: Forskningsbaggrund og -design. Maj 2003.

03-2 Maria Anne Skaates: The International Communication Effects of Sending English Translations of Danish Intellectual Capital Statements to Customers in Great Britain and Germany: Background for and Design of a Research Project. May 2003.

03-3 Rajesh Kumar \& Verner Worm: A Comparative Analysis of Indian and Chinese Negotiating Behavior. June 2003.

03-4 Jørgen Ulff-Møller Nielsen \& Aleksander Rutkowski: The EU anti-dumping policy against non-market economies - The choice of an analogue country and the quality of products. October 2003.

03-5 Robert Green Nielsen, Mai Skjøtt Linneberg and Jens Vestergaard: Organic Consumers'Attitude towards Ecology and Conversion Grade Products. - Focus Group Results. December 2003.

03-6 Jens Vestergaard, Robert D. Goddard and Lotte Brandstrup: Industry Formation and State Invention - The Case of the Windmill Industry in Denmark and the United States. December 2003.

03-7 Edwin C. Duerr and Mitsuko Saito Duerr: An Unconventional Approach to Improving Japan's Economy. December 2003.

03-8 Hanne Nørreklit, Thomas Bendixen, Preben Melander and Lennart Nørreklit: Danish Ideology and Current Management Control: the loss of individual freedom. December 2003.

04-1 Maria Anne Skates: The Theoretical, Methodological, and Practical Background for Looking at International Students' Learning Styles, Backgrounds, and Quality Perceptions with Regard to ASB's Three English-Language M.Sc. Programs. January 2004.

04-2 Lennart Norreklit, Poul Israelsen and Hanne Norreklit: The Validity of Management Control Topoi. Towards Constructivist Pragmatism. January 2004 .

04-3 Jens Vestergaard and Mai Linneberg: The Organic Processing and Wholesale Industry in Denmark 2003. A Qualitative Picture. February 2004.

04-4 Jorgen Ulf-Møller Nielsen and Konrad Pawlik: Locally versus Export Oriented Production. An analysis of foreign capital in Poland 1993-2002. March 2004.

04-5 Jørgen Ulf Møler Nielsen and Konrad Pawhik: Ownership, intra-industry trade and factor intensities: The case of Poland 1993-2002. March 2004. 

04-6 Jai B. P. Sinha and Rajesh Kumar: Methodology for Understanding Indian
Culture. April 2004 .

04-7 Maria Anne Skates: Report on Learning Styles, Backgrounds, and Quality Perceptions of the Students in ASB's Three English-Language M.Sc. Programs. Part 2. May 2004.

04-8 Philipp J. H. Schröder: Real versus TariffLiberalization: A Welfare Comparison under Monopolistic Competition. January 2004. 